\title{
Etiología del síndrome febril agudo sin foco en niños bajo 36 meses de edad que consultan a un servicio de urgencia
}

\author{
Pablo Brockmann V., Ximena Ibarra G., Ignacia Silva W. y Tamara Hirsch B.
}

\section{Etiology of acute fever without source in infants consulting at an emergency department}

Fever is a frequent symptom of consultation in Pediatric Emergency Department. Objectives: to describe causes of acute fever of unknown origin (FUO) in infants under 36 months of age, the utility of requested tests and pediatrician decisions. Patients and Methods: 309 cards of children under 36 months who consulted at Emergency Department for acute FUO were reviewed. Results: $64 \%$ were classified with well clinical condition. Most frequent causes were: probable viral respiratory infections (72\%), urinary tract infection $(7.4 \%)$, pneumonia $(2.9 \%)$, bacteremia $(1.9 \%)$, and bacterial meningitis (1.3\%). Streptococcus pneumoniae was the most frequent agent isolated from blood cultures. Tests of best utility were: urine analysis and urine culture. Leukocytes count $<15.000 / \mathrm{mm}^{3}$ and PCR $<4.0 \mathrm{mg} / \mathrm{dl}$ had a negative predictive value of $96 \%$. Nine point seven percent of the patients were hospitalized, while $14.2 \%$ received antibiotic treatment at home. Conclusions: We suggest to perform urine analysis and culture as the initial study for children with acute FUO and well clinical condition.

Key words: Fever, infant, fever of unknown origin, urinary tract infection. bacteremia.

Palabras claves: Fiebre, lactantes, síndrome febril agudo sin foco, infección urinaria, bacteriemia.

\section{Introducción}

$\mathrm{L}$ a fiebre es uno de los síntomas y signos más frecuentes en niños que consultan en un servicio de urgencia y es el motivo principal de la consulta hasta en 20 a $30 \%$ de las atenciones ambulatorias ${ }^{1-4}$. Durante los dos primeros años de vida, $60 \%$ de los niños consulta alguna vez por este síntoma ${ }^{5}$. La mayoría de las veces el médico clínico hará un diagnóstico que explique la causa de la fiebre; en algunos de los niños bajo 36 meses de edad, aún con una cuidadosa anamnesis y examen físico, el diagnóstico no es evidente. La mayor parte de los niños bajo esta edad, con un síndrome febril agudo sin foco evidente (SFASF), presenta una infección viral autolimitada, que no requiere de tratamiento específico y mejora sin dejar secuelas ${ }^{1,2,4}$. Entre 10 y $25 \%$ pueden estar cursando alguna infección bacteriana grave (IBG) por agentes invasores como bacteriemia, infecciones osteoarticulares, infección del tracto urinario (ITU), o meningitis bacteriana aguda $(\mathrm{MBA})^{4,6-8}$.

Previo al desarrollo y aplicación de la vacuna anti Haemophilus influenzae tipo $b$ (Hib), recomendaciones de la Academia Americana de Pediatría (AAP), sugerían el tratamiento antimicrobiano empírico para tratar las posibles infecciones por agentes invasores en los lactantes febriles, sin foco evidente, que cumplieran con criterios de riesgo para desarrollarlas (temperatura > a 39 ó $39,5^{\circ} \mathrm{C}$ y recuento de leucocitos > $\left.15.000 / \mathrm{mm}^{3}\right)$ y, eventualmente, prevenir así la focalización en el sistema nervioso central ${ }^{7-10}$. Estudios más recientes muestran que las infecciones bacterianas graves, como bacteriemia y MBA, han disminuido en frecuencia ${ }^{10-2}$. La incidencia actual de bacteriemia reportada en la literatura es entre 1 y $2 \%$ en los niños bajo 36 meses de edad, que presentan SFASF y buen aspecto general. Secuelas graves o muerte en estos niños se reportan en menos de $0,3 \%^{10,11}$. En nuestro país, estudios recientes muestran una incidencia de bacteriemia de $1,2 \%{ }^{13}$.

La posibilidad de contar con métodos automatizados de hemocultivo, en los cuales, la mayoría de los agentes invasores causantes de enfermedad grave en los niños son detectados antes de 24 horas de incubación ${ }^{11,14}$, los cambios epidemiológicos señalados, y apreciaciones personales han modificado el enfrentamiento del médico clínico ante un lactante que consulta por un SFASF, apartándose en ocasiones del
Pontificia Universidad Católica de Chile. Santiago, Chile Escuela de Medicina, Departamento de Pediatría

Recibido: 27 septiembre 2005 Aceptado: 21 septiembre 2006

Correspondencia a: Pablo Brockmann Veloso pbrockmann@gmail.com 
cumplimiento estricto de las guías clínicas propuestas por la $\mathrm{AAP}^{15-17}$.

Los objetivos de nuestro estudio fueron: describir la frecuencia y tipos de infecciones bacterianas graves en el niño bajo 36 meses de edad con SFASF que consultó en nuestro servicio de urgencia; describir la conducta de estudio y tratamiento adoptados por el médico clínico; describir los exámenes solicitados y su utilidad en el diagnóstico y tratamiento del SFASF.

\section{Pacientes y Métodos}

En nuestro Servicio de Urgencia existe una guía clínica para el estudio y tratamiento del SFASF (Figura 1), conocida por todos los residentes.

Se revisaron en forma retrospectiva las fichas clínicas de todos los niños bajo 15 años de edad consultantes a la Unidad de Pediatría del Servicio de Urgencia del Hospital Clínico de la Pontificia Universidad
Católica, a partir de abril del 2003, durante un año, y se seleccionaron las fichas pertenecientes a niños de 0 a 36 meses de edad que consultaron por fiebre: $\geq 39{ }^{\circ} \mathrm{C}$ en los de 3 a 36 meses o $\geq 38^{\circ} \mathrm{C}$ en el grupo bajo 90 días de vida, que después de una evaluación clínica no tuvieron un foco evidente. Se excluyó de este estudio a todo niño con algún síntoma o signo que sugiriera al médico un foco clínico causante de la fiebre y/o un diagnóstico. Cumplieron los criterios de inclusión 309 registros correspondientes al mismo número de niños. La ficha de registro del Servicio de Urgencia incluye control de signos vitales al ingreso y, si es necesario, a intervalos según tiempo de estadía o indicación médica. Además, en el ítem examen físico, se consulta un punto específico: impresión de gravedad, donde el residente debe consignar una de las cuatro siguientes categorías: sin gravedad, leve, mediana gravedad, o grave, independiente de la causa de consulta o patología. Se dividieron así los registros en tres grupos según la impresión subjetiva de gravedad y descripción

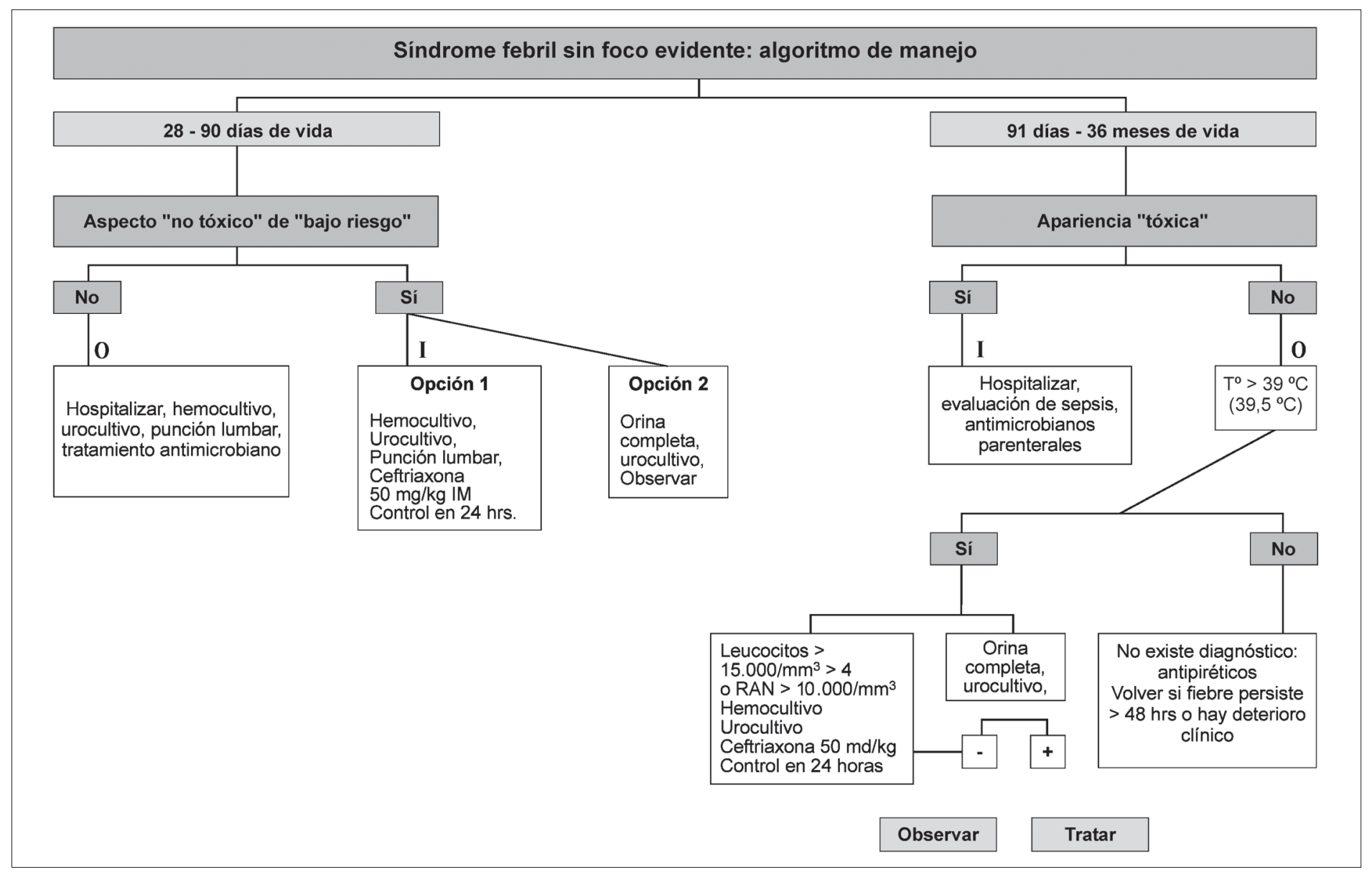

Figura 1. - Bajo riesgo según criterios de Rochester.

- Tomar Rx de tórax sólo si hay síntomas y signos sugerentes de compromiso respiratorio. 
de estado de conciencia, coloración de la piel y signos vitales registrada en la ficha por el residente al momento de la consulta: si el residente marcaba grave y/o describía cambios en estado de conciencia en más o menos, mal llene capilar, piel marmórea y/o taquicardia, se catalogó como aspecto tóxico (AT); si se calificaba sin gravedad o leve y no se describían alteraciones al examen físico, se catalogó de buen aspecto (BA) y de moderado compromiso (MC) a los que no calificaban en los anteriores.

Se registraron datos de la historia, tiempo de evolución de la fiebre, signos vitales, aspecto y examen físico de los niños, exámenes solicitados y sus resultados, el diagnóstico final registrado basado en los exámenes realizados o la evolución del niño en controles en el mismo Servicio de Urgencia y el tratamiento propuesto. Estos datos fueron registrados por tres de los autores (PB, IS, XR), según un protocolo e instructivo preestablecidos y en caso de dudas se sometió a discusión y decisión final por PB.

Se consideró sugerente de infección bacteriana grave recuento de leucocitos $\geq 15.000 / \mathrm{mm}^{3}$ o $<$ a $5.000 /$ $\mathrm{mm}^{3}(5,6)$, PCR $\geq 4 \mathrm{mg} / \mathrm{dL}$, y $/ \mathrm{o}$ VHS $>40 \mathrm{~mm} / \mathrm{h}$, sedimento de orina con leucocitos mayor de 10/campo, piuria y/o presencia de bacterias ${ }^{18}$.

Las características biodemográficas y clínicas del grupo en estudio se presentan como promedios, medianas y desviación estándar y proporciones La comparación entre grupos se hizo con $\chi^{2}$, considerando una diferencia estadísticamente significativa con $\mathrm{p}<0,05$.
Se calcularon los valores predictores. Para el análisis estadístico se usó t de student. Se utilizó el programa SPSS 14.0 y Epidat 3.02003 para los cálculos.

\section{Resultados}

Durante el año del estudio hubo 17.951 consultas a la Unidad de Pediatría del Servicio de Urgencia, 309 $(1,7 \%)$ fueron por SFASF en niños bajo 36 meses de edad. La mediana de edad fue 11 meses (4 días a 35 meses), 297 (92,6\%) eran lactantes sobre 90 días de vida, 12 lactantes bajo 3 meses de edad ( 5 menores de 28 días); 153 (49,5\%) fueron niñas. El promedio de temperatura controlada en el Servicio fue de $39{ }^{\circ} \mathrm{C}$. El 64\% (n: 198) consultó antes de 24 horas de iniciada la fiebre, sin haber diferencias significativas entre grupos etarios.

Dado el bajo número de niños bajo 90 días de vida, los resultados se expondrán y analizarán para el grupo total, sin diferenciar por edad.

Al ingreso fueron catalogados como: BA 197 (64\%), MC 96 (31\%) y AT 17 (5\%). La Tabla 1 muestra los diagnósticos finales registrados en cada uno de estos grupos después de evaluación con exámenes de laboratorio y/o seguimiento clínico en controles en el Servicio de Urgencia. Los diagnósticos realizados con mayor frecuencia: infección respiratoria alta viral (en este grupo se incluyeron los diagnósticos calificados por el residente como: faringitis viral, virosis respi-

Tabla 1. Diagnósticos de egreso en 309 niños consultantes por SFASF* al Servicio de Urgencia según aspecto clínico

\begin{tabular}{|c|c|c|c|c|c|c|c|c|c|}
\hline \multirow[t]{2}{*}{ Diagnóstico } & \multicolumn{2}{|c|}{ Total } & \multicolumn{2}{|c|}{ BA } & \multicolumn{2}{|c|}{ MC } & \multicolumn{2}{|c|}{ AT } & \multirow{2}{*}{$\begin{array}{c}\text { p entre } \\
\text { BA y AT } \\
\text { P }\end{array}$} \\
\hline & $\mathbf{n}$ & $\%$ & $\mathbf{n}$ & $\%$ & $\mathbf{n}$ & $\%$ & $\mathbf{n}$ & $\%$ & \\
\hline IRA viral & 221 & 71,5 & 160 & 81,6 & 54 & 56,3 & 7 & 41,2 & 0,005 \\
\hline ITU & 23 & 7,4 & 9 & 4,6 & 13 & 13,5 & 1 & 5,9 & 0,2 \\
\hline Síndrome febril sin foco & 30 & 9,7 & 15 & 7,7 & 13 & 13,5 & 2 & 11,8 & 0,2 \\
\hline Neumonía & 9 & 2,9 & 3 & 1,5 & 5 & 5,2 & 1 & 5,9 & 0,2 \\
\hline Bacteriemia /sepsis & 6 & 1,9 & 0 & 0,0 & 3 & 3,1 & 3 & 17,6 & 0,001 \\
\hline MBA & 4 & 1,3 & 0 & 0,0 & 1 & 1,0 & 3 & 17,6 & 0,001 \\
\hline Fiebre por vacuna & 3 & 1,0 & 1 & 0,5 & 2 & 2,1 & 0 & 0,0 & 0,7 \\
\hline E. de Kawasaki & 2 & 0,6 & 1 & 0,5 & 1 & 1,0 & 0 & 0,0 & 0,15 \\
\hline SDA & 5 & 1,6 & 5 & 2,6 & 0 & 0,0 & 0 & 0,0 & 0,8 \\
\hline Otros & 6 & 1,9 & 2 & 1,0 & 4 & 4,2 & 0 & 0,0 & 0,6 \\
\hline Total & 309 & 100,0 & 196 & 100,0 & 96 & 100,0 & 17 & 100,0 & - \\
\hline $\begin{array}{l}\text { SFASF: síndrome febril a } \\
\text { IRA =infección respirator } \\
\text { MBA: meningitis bacteria }\end{array}$ & $\begin{array}{l}\text { foco } \\
\text { U: in } \\
\text { SD }\end{array}$ & $\begin{array}{l}\mathrm{BA}: \text { bu } \\
\text { el tracto }\end{array}$ & udo & ano com & AT: & tóxico & & & \\
\hline
\end{tabular}


ratoria, infección respiratoria alta viral) 72\%, ITU 7,4\% y neumonía $2,8 \%$. La frecuencia global de bacteriemia fue de $1,9 \%$ y de MBA $1,3 \%$. Un 9,7\% del total fue catalogado como SFASF, sin diagnóstico específico; en este grupo no hubo hallazgos clínicos ni de laboratorio que orientaran a alguna etiología, la totalidad de estos niños tuvo una evolución favorable y autolimitada, con remisión de la fiebre. La frecuencia de IBG, especialmente bacteriemia/sepsis y MBA fue diferente entre los grupos, siendo significativamente más frecuentes en los grupos MC y AT $(\mathrm{p}<0,05)$.

Fueron hospitalizados en la primera atención 30 $(9,7 \%)$ niños; 10 catalogados como AT, 13 MC y 7 BA.

\begin{tabular}{|c|c|}
\hline Tipo de ATB & $\mathbf{n}$ \\
\hline Ceftriaxona & 25 \\
\hline PCR alta* y/o leucocitosis** & 14 \\
\hline Sospecha de ITU (sedimento alterado) & 4 \\
\hline Síndrome febril sin foco & 7 \\
\hline Amoxicilina & 8 \\
\hline Radiografía de tórax alterada & 2 \\
\hline PCR alta y/o leucocitosis & 1 \\
\hline Otitis media aguda & 5 \\
\hline Cefadroxilo & 13 \\
\hline Sospecha de ITU (sedimento alterado) & 13 \\
\hline Cefuroxima axetil & 1 \\
\hline Causa no registrada & 1 \\
\hline Total & 47 \\
\hline $\begin{array}{l}\text { SFASF: síndrome febril agudo sin foco evide } \\
\text { * PCR }>4 \mathrm{mg} / \mathrm{dL} \\
\text { ** Recuento de leucocitos } \geq 15.000 / \mathrm{mm}^{3}\end{array}$ & \\
\hline
\end{tabular}

La justificación para la hospitalización de los lactantes BA fue: 2 por mala tolerancia oral, 2 por sospecha de ITU en el grupo bajo 3 meses de edad y 3 por ser recién nacidos febriles. Se indicó tratamiento antimicrobiano en régimen ambulatorio a $47(14,2 \%)$ de los niños que no se hospitalizaron, a 17 (36\%) de ellos fue por sospecha de ITU. En la Tabla 2 se detallan los antibacterianos utilizados y la justificación del médico para indicarlos.

Los exámenes de laboratorio solicitados y la frecuencia de estos varió según el aspecto clínico del niño al momento de la consulta; así, se le realizó algún examen a $26 \%$ del grupo BA, a $46 \%$ de los MC y a $76 \%$ de los AT, siendo estadísticamente significativa la diferencia entre BA y AT $(\mathrm{p}<0,05)$. El análisis de orina y urocultivo fue el examen más frecuentemente solicitado (48,5\%), seguido de hemograma y PCR $(31,7 \%)$. Se realizó una radiografía de tórax a 12 niños, 3 informadas como normales y 9, sugerentes de neumonía. En la Tabla 3 se resume la frecuencia de exámenes de laboratorio realizados según grupo.

Los análisis de orina y urocultivo fueron los exámenes que con mayor frecuencia resultaron anormales, especialmente en el grupo BA. El hemograma y PCR resultaron alterados con mayor frecuencia en el grupo AT. En la Tabla 4 se resume la frecuencia de exámenes alterados por grupo.

El recuento de leucocitos $>15.000 / \mathrm{mm}^{3}$ tuvo una sensibilidad (S) de 40\%, especificidad (E) de $89 \%$, valor predictor positivo (VPP) $16,6 \%$ para infección bacteriana; un recuento de leucocitos $<15.000 / \mathrm{mm}^{3}$, valor predictor negativo (VPN) de $96,5 \%$ para desarrollar una IBG. Una PCR > 4,0 mg/dL tuvo una S 33,3\%, E 97,9\%, VPP 33,3\%; a su vez, un valor de PCR $<4$ mg/dL arrojó un VPN de $97,8 \%$.

Se aisló un microorganismo patógeno en 6 de 85 (7\%) hemocultivos realizados Streptococcus pneumoniae (n: 3), Eschericha coli (n:1), Streptococcus pyogenes (n:1), y Streptococcus grupo viridans (n:1).

\begin{tabular}{|c|c|c|c|c|c|c|c|c|}
\hline & \multicolumn{2}{|c|}{ Total } & \multicolumn{2}{|c|}{ BA } & \multicolumn{2}{|c|}{ MC } & \multicolumn{2}{|c|}{ AT } \\
\hline & $\mathbf{n}$ & $\%$ & $\mathbf{n}$ & $\%$ & $\mathbf{n}$ & $\%$ & $\mathbf{n}$ & $\%$ \\
\hline Hemograma & 98 & 31,7 & 43 & $21,9 *$ & 53 & 55 & 11 & 68,8 \\
\hline$P C R$ & 98 & 31,7 & 43 & $21,9 *$ & 53 & 55 & 11 & 68,8 \\
\hline Hemocultivo & 96 & 31,1 & 40 & $20.4^{*}$ & 45 & 46,8 & 11 & 64,7 \\
\hline Sedimento de orina & 150 & 48,5 & 76 & $38,5^{*}$ & 60 & 62,5 & 14 & 87,5 \\
\hline Urocultivo & 150 & 48,5 & 76 & $38,5^{*}$ & 60 & 62,5 & 14 & 87,5 \\
\hline
\end{tabular}




\begin{tabular}{|c|c|c|c|c|c|c|}
\hline & \multicolumn{2}{|c|}{ BA } & \multicolumn{2}{|c|}{ MC } & \multicolumn{2}{|c|}{ AT } \\
\hline & $\mathbf{n}$ & $\%$ & $\mathbf{n}$ & $\%$ & $\mathbf{n}$ & $\%$ \\
\hline Hemograma* & $12 / 43$ & 28 & $14 / 53$ & 26 & $4 / 11$ & 36 \\
\hline$P C R \geq 4 \mathrm{mg} / \mathrm{dL}$ & $6 / 43$ & 14 & $19 / 53$ & 35 & $5 / 11$ & 45 \\
\hline Hemocultivo con agente patógeno & $0 / 40$ & 0 & $1 / 45$ & 2 & $5 / 11$ & 45 \\
\hline Análisis completo de orina & $13 / 76$ & 13 & $10 / 60$ & 17 & $1 / 14$ & 7 \\
\hline Urocultivo & $6 / 76$ & 7,8 & $8 / 60$ & 14 & $1 / 14$ & 7 \\
\hline Citoquímico LCR & $0 / 2$ & 0 & $1 / 7$ & 14 & $3 / 9$ & 33 \\
\hline Cultivo LCR positivo para bacteria & $0 / 2$ & 0 & $1 / 7$ & 14 & $3 / 9$ & 33 \\
\hline $\begin{array}{l}\text { SFASF: síndrome febril agudo sin fo } \\
\text { *Hemograma alterado: recuento de }\end{array}$ & $15.000 /$ & ${ }^{3} 0<$ & & & & \\
\hline
\end{tabular}

Tres de los niños, cuyos hemocultivos fueron positivos, tenían AT al momento de la consulta: $S$. pneumoniae (n: 2) y S. pyogenes (n: 1), se hospitalizaron, recibieron antibioterapia desde su ingreso y tuvieron buena evolución. Los tres niños restantes se catalogaron MC; uno de ellos reconsultó a las pocas horas con aspecto tóxico y presentó una MBA (se le efectuó punción lumbar en la segunda consulta), el hemocultivo tomado en la primera consulta se hizo positivo a las 9 horas para $S$. pneumoniae. Los otros dos se hospitalizaron por ser RN febriles (Streptococcus grupo viridans, E. coli).

\section{Discusión}

Los resultados obtenidos en este estudio retrospectivo y descriptivo muestran que en nuestro medio la consulta por fiebre es precoz, habitualmente antes de 24 horas y al igual que lo publicado en la literatura extranjera $^{1,4,10,12}$, la mayoría de los niños bajo 36 meses de edad que consultan por fiebre sin foco y buen aspecto general, presentan una enfermedad benigna y autolimitada, predominantemente de causa viral. La presencia de IBG en nuestra serie es similar a lo reportado por otros autores ${ }^{1,4,10-12}$. Destaca como principal causa de IBG la ITU, cuya incidencia en nuestra serie es algo mayor al $5 \%$ publicado $^{10,19-21}$; en el grupo BA fue de 5,6\%, aunque se realizó examen de orina sólo a $37 \%$ de los niños de este grupo, lo que muestra una tasa específica de $21 \%$, claramente mayor que lo reportado en la literatura. Lizama y cols mostraron una frecuencia similar en este grupo etario y fiebre fue el síntoma principal previo a la consulta en $90 \%$ de los lactantes con ITU ${ }^{18}$.
La presencia de bacteriemia y/o sepsis en nuestros niños fue similar a lo reportado. Lagos y cols comunicaron una frecuencia de $1,2 \%$ de hemocultivos positivos en lactantes chilenos con fiebre de $40^{\circ} \mathrm{C}$ o más ${ }^{13}$. Estudios extranjeros describen frecuencias de 1 a $3 \%$ de bacteriemia. Esta varía según la edad de los lactantes: en RN se reporta entre 3 y $5 \%$; en el grupo entre 1 y 3 meses de edad $1-2 \%$, y sobre 3 meses de edad alrededor de $1 \%{ }^{10-12,22-24}$. Sólo $12(7,4 \%)$ niños de nuestra serie tenían bajo 90 días de vida, lo que no permite hacer comparaciones estadísticamente aceptables entre este grupo y mayores.

El agente infeccioso aislado con mayor frecuencia fue $S$. pneumoniae. Esto es concordante con lo publicado en Chile y en el extranjero a partir de la introducción de la vacuna conjugada anti $H$. influenzae tipo $\mathrm{b}^{11,12,25}$.

La frecuencia de MBA en nuestra serie fue algo superior a lo reportado en la literatura extranjera ${ }^{10,11}$. Baraff y cols reportaron en un meta-análisis una incidencia de $0,8 \%$ de MBA en 1.703 lactantes febriles con buen aspecto general ${ }^{22}$. Estudios más recientes, posteriores a la introducción de la vacuna anti-neumocóccica conjugada heptavalente, reportan incidencias de alrededor de $0,5 \%$ en lactantes bajo tres meses de edad $^{12,25,26}$. Esta mayor frecuencia de MBA en nuestra serie, podría deberse a que la población estudiada fue menor en número y a la inclusión de niños febriles con buen aspecto general, medianamente comprometidos y de aspecto tóxico. El único caso de MBA que no tenía aspecto tóxico, correspondió al grupo MC en su primera consulta y reconsultó a las pocas horas por persistencia de fiebre alta y empeoramiento de su estado general; ingresando en esa oportunidad con aspecto tóxico. 
La bacteriemia estuvo ausente en los niños de BA, hallazgo que, probablemente, se debe al bajo número de casos, pero que muestra la tendencia a la disminución, al igual que en otros países, como se ha comentado anteriormente.

En el grupo MC y AT se solicitaron significativamente más exámenes de laboratorio. La conducta del médico, en relación al aspecto clínico de un lactante con SFASF, ha sido evaluada en diversos estudios ${ }^{15-17,27}$. Existe la tendencia a solicitar más y con mayor frecuencia, exámenes a los niños del grupo de peor aspecto general $^{17,27}$, concordante con lo registrado en nuestra serie. En el grupo AT no se solicitó exámenes en el Servicio de Urgencia al $100 \%$ de los pacientes, en algunos casos se realizaron una vez que el niño se encontraba hospitalizado en el Servicio de Pediatría. En el grupo BA, los análisis de orina completa y urocultivo fueron los exámenes más solicitados. Hubo diferencias en el cumplimiento de las recomendaciones de las Guías Clínicas de acuerdo con la edad de los niños. Ésta fue significativamente mayor en el grupo bajo 28 días de vida y en el grupo de 28 a 90 días, fenómeno ya descrito por otros autores ${ }^{17}$.

La solicitud de hemograma y PCR es frecuente, se realiza en 70 a $95 \%$ de todos los niños con SFASF que consultan a un Servicio de Urgencia ${ }^{27}$. El recuento de leucocitos y la PCR tienen limitaciones en la pesquisa de $\mathrm{IBG}^{27}$. Bonsu y cols describieron una sensibilidad y especificidad pobres en la identificación de IBG, utilizando como punto de corte menos de 5.000 ó 15.000 o más leucocitos $/ \mathrm{mm}^{3}{ }^{28}$. El recuento de leucocitos > $15.000 / \mathrm{mm}^{3}$ y PCR $>4,0 \mathrm{mg} / \mathrm{dL}$ en nuestra serie tuvo una buena especificidad pero muy baja sensibilidad. Lo rescatable es el alto VPN, similar a lo encontrado por Pullian ${ }^{29}$, quien con una PCR $<5 \mathrm{mg} / \mathrm{dL}$ sugiere que se descarta una infección bacteriana grave. Recomendamos su solicitud en niños de aspecto MC o AT, teniendo en cuenta que un recuento de leucocitos bajo $15.000 / \mathrm{mm}^{3}$ y una PCR $<4,0 \mathrm{mg} / \mathrm{dL}$, hacen menos probable la presencia de una IBG.

La frecuencia de solicitud de hemocultivos en nuestra serie es concordante con lo publicado ${ }^{11,27}$ y los agentes infecciosos encontrados son similares a lo descrito $^{11}$ destacando $S$. pneumoniae como principal agente infeccioso productor de bacteriemias y sepsis, en la era posterior a la introducción al PAI de vacuna anti $H$. influenzae tipo $\mathrm{b}^{12,26}$.

Se indicó tratamiento con antibacterianos en régimen ambulatorio a $15 \%$ de los niños, justificándose esta indicación, en un análisis de orina alterado o leucocitosis $>15.000 / \mathrm{mm}^{3}$ o PCR "alterada", como se recomienda en las guías clínicas de la AAP publicadas en el año $2003^{2}$. Estudios realizados en la era pre vacuna anti $H$. influenzae tipo b apoyaban el uso de cefalosporinas de tercera generación en forma empírica en niños con temperatura mayor a $39,5{ }^{\circ} \mathrm{C}$ y leucocitosis $>15.000 / \mathrm{mm}^{3}{ }^{30,31}$; dos meta-análisis más recientes no muestran beneficios en la reducción de MBA ni secuelas en niños con bacteriemias ocultas por S. pneumoniae tratados "profilácticamente" con antimicrobianos ${ }^{32,33}$. Esto, sumado al aumento de aislados de $S$. pneumoniae resistentes a penicilina y cefalosporinas, hace discutible y necesario reevaluar la conducta de indicar antimicrobianos parenterales en espera de los resultados de hemocultivos.

Los exámenes de laboratorio que con mayor frecuencia ayudaron al diagnóstico y conducta final del clínico tratante fueron los análisis de orina completa y urocultivo. Basados en nuestros resultados y las pautas publicadas ${ }^{2}$, sugerimos orientar el estudio de los niños bajo 36 meses de edad con SFASF según su aspecto clínico y edad; así, en el grupo de BA, iniciar el estudio con análisis de orina y urocultivo parece altamente recomendable, dado que la ITU, es la causa más frecuente de IBG en ellos. En el grupo de AT y en los neonatos (bajo 28 días de vida) el estudio debería ser más completo con hemograma, PCR, hemocultivo y estudio de LCR, además de los exámenes de orina.

\section{Resumen}

La fiebre es uno de los síntomas frecuentes de consulta en Servicios de Urgencia pediátricos. $\mathrm{Ob}$ jetivos: Describir causas del síndrome febril agudo sin foco evidente (SFASF) en niños bajo 36 meses de edad, utilidad de exámenes solicitados y conducta del médico. Pacientes y Métodos: Se analizaron 309 fichas de niños bajo 36 meses, que consultaron en el servicio de urgencia por SFASF. Resultados: $64 \%$ fue catalogado de buen aspecto clínico al ingreso. Las causas más frecuentes fueron infecciones probablemente virales respiratorias $72 \%$, infección urinaria $7,4 \%$, neumonía $2,9 \%$, bacteriemia $1,9 \%$ y meningitis bacteriana $1,3 \%$. Streptococcus pneumoniae fue el agente más frecuentemente aislado de sangre. Los exámenes de mayor utilidad fueron sedimento de orina y urocultivo. Un recuento de leucocitos $<15.000 / \mathrm{mm}^{3}$ y $\mathrm{PCR}<4,0 \mathrm{mg} / \mathrm{dL}$ tuvieron un valor predictor negativo de $96 \%$. Se hospitalizó a 9,7\% de los niños, $14,2 \%$ recibió antimicrobianos ambulatorios. Conclusiones: Sugerimos como estudio inicial del niño con SFASF y de buen aspecto general, la realización de un examen de orina con urocultivo. 


\section{Referencias}

1.- Bandyopadhyay S, Bergholte J, Blackwell C D, Friedlander J R, Hennes H. Risk of serious bacterial infection in children with fever without a source in the post-Haemophilus influenzae era when antibiotics are reserved for culture-proven bacteremia. Arch Pediatr Adolesc Med 2002; 156: 512-7.

2.- American College of Emergency Physicians Clinical Policies Committee. Clinical policy for children younger than three years presenting to the emergency department with fever. Ann Emerg Med 2003; 42: 53045.

3.- Kuppermann N, Fleisher G R, Jaffe D M. Predictors of occult pneumococcal bacteremia in young febrile children. Ann Emerg Med 1998; 31: 679-87.

4.- Finkelstein J A, Christiansen C L, Platt R. Fever in pediatric primary care: occurrence, management, and outcomes. Pediatrics 2000; 105: 260-6.

5.- Baraff L J, Lee S I. Fever without source: management of children 3 to 36 months of age. Pediatr Infect Dis J 1992; 11: 146-51.

6.- Bleeker S E, Moons K G, Derksen-Lubsen G, Grobbee D E, Moll H A. Predicting serious bacterial infection in young children with fever without apparent source. Acta Paediatr 2001; 90: 1226-32.

7.- Baraff L J, Bass J W, Fleisher G R, Klein J O, McCracken G H Jr, Powell K R, et al. Practice guideline for the management of infants and children 0 to 36 months of age with fever without source. Agency for Health Care Policy and Research. Ann Emerg Med 1993; 22: 1198-210.

8.- Baraff L J, Schriger D L, Bass J W, Fleisher G R, Klein J O, Mc Cracken G H Jr, et al. Practice guideline for the management of infants and children 0-36 month of age with fever without source Pediatrics 1993; 92: 1-12.

9.- Dagan R, Powell K R, Hall C B, Menegus M A. Identification of infants unlikely to have serious bacterial infection although hospitalized for suspected sepsis. J Pediatr 1985; 107: 855-60.

10.- Pantell R H, Newman T B, Bernzweig J, Bergman D A, Takayama J I, Segal M, et al. Management and outcomes of care of fever in early infancy. JAMA 2004; 291: $1203-$ 12.

11.- Alpern E R, Alessandrini E A, Bell L M,
Shaw K N, McGowan K L. Occult bacteremia from a pediatric emergency department: current prevalence, time to detection, and outcome. Pediatrics 2000; 106: 505-11.

12.- Lee G M, Harper M B. Risk of bacteremia for febrile young children in the post Haemophilus influenzae type $\mathrm{b}$ era. Arch Pediatr Adolesc Med 1998; 152: 624-8.

13.- Lagos R, Muñoz A, Valenzuela M T, Heitmann I, Levine M M. Population-based surveillance for hospitalized and ambulatory pediatric invasive pneumococcal disease in Santiago, Chile. Pediatr Infect Dis J 2002; 21: 1115-23.

14.- McGowan K L, Foster J A, Coffin S E. Outpatient pediatric blood cultures: time to positivity. Pediatrics 2000; $106(2 \mathrm{Pt} 1)$ : 251-5.

15.- Bekfer R A, Gittelman M A, Muniz A E. Management of febrile infants and children by pediatric emergency medicine: comparison with practice guidelines. Pediatr Emerg Care 2001; 17: 83-87.

16.- Ros S P, Herman B E, Beissel T J. Occult bacteremia: is there a standard of care? Pediatr Emerg Care 1994; 10: 264-7.

17.- Zerr D M, Del Beccaro M A, Cummings P. Predictors of physician compliance with a published guideline on management of febrile infants. Pediatr Infect Dis J 1999; 18: 2328.

18.- Lizama M, Luco M, Reichhard C, Hirsch T Infección del tracto urinario en un servicio de urgencia pediátrico: Frecuencia y características clínicas. Rev Chil Infectol 2005; 22: 235-41.

19.- Hoberman A, Chao H P, Keller D M, Hickey R, Davis H W, Ellis D. Prevalence of urinary tract infection in febrile infants $\mathrm{J}$. Pediatr 1993; 123: 17-23.

20.- Shaw K N, Gorelick M, McGowan K L, Yakscoe N M, Schwartz J S. Prevalence of urinary tract infection in febrile young children in the emergency department. Pediatrics 1998; 102: e16.

21.- Hoberman A, Wald E R. Urinary tract infection in young febrile children. Pediatr Infect Dis J 1997; 16: 11-7.

22.- Baraff L J, Oslund S A, Schriger D L, Stephen M L. Probability of bacterial infections in febrile infants less than three months of age: a meta-analysis. Pediatr Infect Dis J 1992; 11: 257-64.

23.- Baskin M N. The prevalence of serious bacterial infections by age in febrile infants during the first three months of life. Pediatr Ann 1993; 22: 462-6.

24.- Byington C L, Rittichier K K, Bassett K E, Castillo H, Glasgow T S, Daly J, et al. Serious bacterial infections in febrile infants younger than 90 days of age: the importance of ampicillin-resistant pathogens. Pediatrics 2003; 111: 964-8.

25.- Ruvinsky R, Gentile A, Regueira M. Infecciones invasivas por Streptococcus pneumoniae: Estudio epidemiológico e importancia del desarrollo de un sistema de vigilancia. Rev Chil Pediatr 2004; 75: 77-9.

26.- Klein J. Management of the febrile child without a focus of infection in the era of universal pneumococcal immunization. Pediatr Infect Dis J 2002; 21: 584-8

27.- Green S M, Rothrock S G. Evaluation styles for well-appearing febrile children: Are you a "risk-minimizer" or a "test-minimizer"? Ann Emerg Med 1999; 33: 211-4.

28.- Bonsu B K, Harper M B. Identifying febrile young infants with bacteremia: is the peripheral blood cell count an accurate screen? Ann Emerg Med 2003; 42: 216-25.

29.- Pulliam P N, Attia M W, Kronan K M. C-reactive protein in febrile children 1 to 36 months of age with clinically undetectable serious bacterial infection. Pediatrics 2001; 108: 1275 - 9.

30.- Bass J W, Steele R W, Wittler R R, Weisse M E, Bell V, Heisser A H, et al. Antimicrobial treatment of occult bacteremia: a multicenter cooperative study. Pediatr Infect Dis J 1993; 12: 466-73.

31.- Fleisher G R, Rosenberg N, Vinci R, Steinberg J, Powell K, Christy C, et al. Intramuscular versus oral antibiotic therapy for the prevention of meningitis and other bacterial sequelae in young, febrile children at risk for occult bacteremia. J Pediatr 1994; 124: 504-12.

32.- Rothrock S G, Harper M B, Green S M, Clark M C, Bachur R, McIlmail D P, et al. Do oral antibiotics prevent meningitis and serious bacterial infections in children with Streptococcus pneumoniae occult bacteremia? A meta-analysis. Pediatrics 1997; 99: 438-44.

33. - Bulloch B, Craig W R, Klassen T P. The use of antibiotics to prevent serious sequelae in children at risk for occult bacteremia: a meta-analysis. Acad Emerg Med 1997; 4: 679-83. 